\title{
User Involvement And Satisfaction Levels Of Health Information Systems During The Design And Development Phase
}

\author{
Gonza Omoro ${ }^{a}$, Prof. Solomon Ogara ${ }^{a}$, Dr. Joshua Agola ${ }^{a}$ \\ gonza.omoro123@gmail.com, solomon.ogara@gmail.com, agolaus@gmail.com \\ a Jaramogi Oginga Odinga University of Science and Technology, P.O Box 210-40601, Bondo, Kenya
}

\begin{abstract}
Objectives: Many factors affect adoption of health information systems, user involvement and satisfaction are some of the main factors of user adoption of health information systems. Despite the benefits due to social, cultural, organizational and technological factors some of the benefits become complex and difficult to achieve in practice. Both users and development team lack time due to busy schedules, sometimes disagreements between the users and the project team to reach concurrence, user at time might lack the necessary skills and knowledge to effectively participate in the design process. This study will investigate the user involvements and satisfaction levels of health information systems during the design and development phase.

Methods: Cross sectional survey was utilized. Several existing tools were modified and used for the study namely Patient Satisfaction Questionnaire, Usefulness, Satisfaction, and Ease of use (USE) Questionnaire and Purdue Usability Testing Questionnaire. Structured equation models (SEM) analysis was used in the analysis. Ordinal regression statistics was used.

Results: User involvement and satisfaction measure as the dependent variable and the user participation during the design and development of the health information systems as the independent variables. For every one unit increase in independent variable there is a predicted increase (of a certain amount) in the log odds falling at a higher level of the dependent variable. Generally showing that as scores increase on the independent variables, there is an increase probability falling at a higher level on the dependent variable.

Conclusions: User involvement and participation has positive impact on the satisfaction levels of users during the design and development of the health information system.
\end{abstract}

Keywords: User Involvement, User Participation, User Satisfaction, Systems Design and Devement

\subsection{Introduction}

The widespread of use of Information and Communication Technologies (ICT) has permeated almost all aspects of life including health sector (Almunawar \& Anshari, 2012). Health information systems (HIS) is critical in health care delivery. Health IS has the potential to improve the health of individuals and the performance of providers (Buntin, 2011), yielding improved quality, cost savings and greater engagement by the patients in their own health care (Buntin, 2011). Despite evidence of these benefits, physicians and hospitals use of health IT and electronic health records still low (Buntin, 2011), even though the use of Health IS is seen as having a lot benefits to health care delivery, Marcial describes this as a "wicked problem," 
referring to the complex web of stakeholders, systems, and legislative parameters involved (Marcial, 2014). The use health ICT requires a unique attention due to its complexity unpredictability and the erratic nature (Marcial, 2014).

To enhance the quality of health services and to reduce their costs, health organizations recognize the need of making investments in information technologies (Sebetci, 2018). It is a fact that an effective health information system must be used to achieve efficiency, productivity, service quality and customer satisfaction of the stakeholders of the health sector (Sebetci, 2018). Several research show that health information technology has the potential to improve healthcare through enhancing efficiency and safety, this benefit has never been fully realized (Tanga, Limc, Mansfieldc, McLachlanf, \& Quanc, 2018). Some of the challenges are due to non-technical issues like poor usability arising from lack of user involvements, thus affect workflows and communication amongst the user teams (Tanga, Limc, Mansfieldc, McLachlanf, \& Quanc, 2018).

User involvement during the design and development is one of the approaches of achieving this. This is provided for through three methods ie a) through user centered design where the designer carefully studies and fully understands the users' perspective and experiences to ensure that the product developed is/will be useful and usable to them (Tanga, Limc, Mansfieldc, McLachlanf, \& Quanc, 2018). b) user codesign, this is where the designer and the user work together to design the product, thus gives the user more control in the design phase of the health information systems. This is achieved through strategies like prototyping and simulation. (Tanga, Limc, Mansfieldc, McLachlanf, \& Quanc, 2018). c) Participatory design where the user has a voice and participate fully in the design of the product, the user get involved in the innovations and participate in the decision making (Tanga, Limc, Mansfieldc, McLachlanf, \& Quanc, 2018).

Many factors affect adoption of health information systems, Lee et al. evaluated user satisfaction and computerized provider order entry (CPOE) function and found that the overall user satisfaction as one of the main factors of user adoption of health information systems. According to Technology Acceptance Model (TAM), perceived usefulness and perceived ease of use are two fundamental determinants of user satisfaction and utilization. (Palm, Determinants of User Satisfaction with a Clinical Information System, 2006). Some of the benefits of user involvement include:

a) Leads to improved systems quality since the user requirements were captured accurately

b) Further the useful features and included and the unnecessary features are excluded

c) Increased user acceptance an adoption during the implementation

d) Decreased training need due to high understanding of the system by the users.

e) Increased participation by the users in the organization.

Tanga et al. argues that despite all these benefits due to social, cultural, organizational and technological factors some of the benefits become complex and difficult to achieve in practice. (Tanga, Limc, Mansfieldc, McLachlanf, \& Quanc, 2018). Both users and development team lack time due to busy schedules, sometimes disagreements between the users and the project team to reach concurrence, user at time might lack the necessary skills and knowledge to effectively participate in the design process (Tanga, Limc, Mansfieldc, McLachlanf, \& Quanc, 2018). This study will investigate the user involvements and satisfaction levels of health information systems during the design and development phase.

\subsection{Methods}

Cross sectional survey design was used to conduct this survey, this is whether study participants were randomized and included in the study and asked to participate in the study. The target population comprised selected systems users ie health practitioners, and the systems development team. The total number 
of facilities targeted was 99 (both level 4 \&5) with a total health care population of 8000 . Assumption was be made that they are a representation of all the health facilities in the study counties of Kisumu, Kakamega, Busia, Vihiga, Bungoma, Homabay, Siaya, and Migori in Kenya. Two systems developers from each of the two large national software organization will be selected. Five hospital patients were purposely randomly selected from each hospital. The sample size was comprise of 152 respondents. Each county had 15 participants split into 8 from level 5 facility and 7 coming from level 4 facilities. Usefulness, Satisfaction, and Ease of use (USE) Questionnaire developed by Lund et al 1986 was used with modifications. Purdue Usability Testing Questionnaire by Lin, 1997 was used with modifications.

Regarding user participation using the information systems development stages, tools derived from (Barki \& Hartwick, 1994)were used to measure these constructs. For user involvement we used the categorization provided by (Manuel, Pastor, \& Casanovas, 2003) ie user process involvement and user systems involvement to derive the questions that were administered. During validation specific to improved healthcare measurement, the Patient Satisfaction Questionnaire (PSQ-18) which is a short form version of the original PSQ developed by Ware, Snyder, and Wright, 1976 was modified and used. The PSQ sub-scales show acceptable internal consistency reliability. Data was captured using questionnaires developed using 7 point Likert scale method. The questionnaire

Structured equation models (SEM) analysis was used. This technique combines factor analysis and multiple regression analysis, and analyses the structural relationship between measured variables and latent constructs. This would helped analyze satisfaction levels of users. SEM was used to estimate the relations between the latent variables e.g satisfaction levels and between the manifest variables e.g age, sex and the latent variables.

\subsection{Data Analysis}

\subsection{DISTRIBUTION OF RESPONDENTS BY AGE GROUPS}

One hundred and fifty two (152) respondents were interviewed, spread across the targets 8 western Kenya counties of Kisumu Siaya, Kakamega, Vihiga, Bungoma, Busia, Homabay and Migori. 69.7\% of them were aged 26 and 35 years old, $27.6 \%$ were between 36 and 45 years old while only $2.6 \%$ were 25 years ae below.

Table 1: Distribution of respondents by age groups

\begin{tabular}{lllll}
\hline County & $\begin{array}{l}\text { Less than 26 years } \\
\text { Old }\end{array}$ & $\begin{array}{l}\text { Between } \\
\text { 35 years Old }\end{array}$ & $\begin{array}{l}\text { Between } 36 \text { and } \\
\text { years Old }\end{array}$ & Total \\
\hline Kisumu & 0 & 15 & 4 & 19 \\
Kakamega & 0 & 16 & 3 & 19 \\
Vihiga & 0 & 6 & 13 & 19 \\
Busia & 3 & 16 & 0 & 19 \\
Bungoma & 0 & 13 & 6 & 19 \\
Homabay & 0 & 15 & 4 & 19 \\
Migori & 1 & 13 & 7 & 19 \\
Siaya & 0 & 12 & $\mathbf{4 2}(\mathbf{2 7 . 6 \% )}$ & 19 \\
Total & $\mathbf{4}(\mathbf{2 . 6 \% )}$ & $\mathbf{1 0 6}(\mathbf{6 9 . 7 \% )}$ & & $\mathbf{1 5 2}(\mathbf{1 0 0 \%})$ \\
\end{tabular}




\subsection{DISTRIBUTION OF RESPONDENTS BY LENGTH OF SERVICE, EDUCATION LEVEL, DESIGNATION}

About $41 \%$ of the respondents have between 5 to 9.9 years of services, $29 \%$ of them had between 2 4.9 years of service, $23 \%$ have less than 2 years of service while only 7.2 of the respondents has over 10 years of service. More than half of the respondents had college diploma education level, $24 \%$ of them had university degree while $9.9 \%$ had certificate education level. Majority $(58.6 \%)$ of the respondents were health records and information officers, $18.4 \%$ of them were clinical officers, $21.1 \%$ were nurses and $2 \%$ of them were financial officers. Slightly more than half of the respondents were males while $48 \%$ of them were females.

Most of the respondents $(87.5 \%)$ had been trained in the current health information system in use in their respective facilities. Only $12.5 \%$ had not been training on the current health information system in use in their respective facilities

Table 2: Distribution of Respondents by Length of Service, Education Level, Designation

\begin{tabular}{|c|c|c|}
\hline Length of Service & Frequency & Percent \\
\hline Over 10yrs & 11 & 7.2 \\
\hline Between 5-9.9yrs & 62 & 40.8 \\
\hline Between 2-4.9yrs & 44 & 28.9 \\
\hline Less than $2 \mathrm{yrs}$ & 35 & 23.0 \\
\hline Total & 152 & 100.0 \\
\hline \multicolumn{3}{|l|}{ Education Level } \\
\hline College Certificate & 15 & 9.9 \\
\hline College Diploma & 101 & 66.4 \\
\hline University degree & 36 & 23.7 \\
\hline Total & 152 & 100.0 \\
\hline \multicolumn{3}{|l|}{ Designation } \\
\hline Nurse & 32 & 21.1 \\
\hline Clinical Officer & 28 & 18.4 \\
\hline Financial Officer & 3 & 2.0 \\
\hline Health Records Information Officer & 89 & 58.6 \\
\hline \multicolumn{3}{|l|}{ Sex } \\
\hline Male & 79 & 52.0 \\
\hline Female & 73 & 48.0 \\
\hline Total & 152 & 100.0 \\
\hline \multicolumn{3}{|c|}{$\begin{array}{l}\text { Have you been trained on the current health } \\
\text { information in use in this facility }\end{array}$} \\
\hline Yes & 133 & 87.5 \\
\hline No & 19 & 12.5 \\
\hline Total & 152 & 100.0 \\
\hline
\end{tabular}




\subsection{RESPONDENTS TRAINING ON THE CURRENT HEALTH INFORMATION IN USE IN THE F ACILITY AND LENGTH OF SERVICE}

Results show that respondents who had served in the facilities for between 5-9.9 years old had many of them trained that the others, followed by those who had served for less than 2 years in the facilities and those between 2-4.9 years of service.

Table 3: Distribution of respondents by the current health information in use and length of service

\begin{tabular}{llll}
\hline & Trained in HIS & & \\
Length of Service & Yes & No & Total \\
Over 10yrs & $4(36.4 \%)$ & $7(63.6 \%)$ & $11(100 \%)$ \\
Between 5-9.9yrs & $62(100 \%)$ & $0(0 \%)$ & $62(100 \%)$ \\
Between 2-4.9yrs & $32(72.7 \%)$ & $12(27.3 \%)$ & $44(100 \%)$ \\
Less than 2yrs & $35(100 \%)$ & $0(0 \%)$ & $35(100 \%)$ \\
& $133(87.5 \%$ & $19(12.5 \%)$ & $152(100 \%)$ \\
\hline
\end{tabular}

\subsection{TO INVESTIGATE USER INVOLVEMENT AND SATISFACTION LEVELS IN HEALTH INFORMATION SYSTEMS DURING THE DESIGN AND DEVELOPMENT PHASE}

\subsubsection{User Participation -Physical Design Phase}

Only about a quarter of the respondents had main responsibility for the development project during physical design, while $85.5 \%$ of them did not have a main responsibility for the development project during physical design. Equal respondents agreed and disagreed that the Information systems/data processing staff drew up a formalised agreement of the work to be done during system physical design. $25 \%$ of the respondents were able to make changes to the formalised agreement of work to be done during system physical design while $75 \%$ of them were not able to make changes to the formalised agreement of work to be done during system physical design. Close of half of the respondents said that the information systems/data processing staff kept me informed concerning progress and/or problems during system physical design, while 52\% of them were not kept me informed concerning progress and/or problems during system physical design by the information systems/data processing staff. $38.2 \%$ of the respondents did formally review the work done by information system/data processing staff during system physical design, while $61.8 \%$ did not review the work done by information system/data processing staff during system physical design.

Only $25.7 \%$ of the respondents formally approved work done by information system/data processing staff during system physical design, while 74.3 did not respondents formally approved work done by information system/data processing staff during system physical design. $25 \%$ of the respondents signed off a formalised agreement of the work by the information systems/data processing staff during system physical design while $75 \%$ of them did not sign off a formalised agreement of the work by the information systems/data processing staff during system physical design. Below $35 \%$ of the respondents helped define input/output forms, screen layouts, report formats, development systems controls, and security procedures for the health information systems. $35.5 \%$ of the respondents evaluated systems controls and /or security procedures developed by information systems/data processing, while $64.5 \%$ of them did not evaluate systems controls and /or security procedures developed by information systems/data processing. Only $25.7 \%$ of the respondents approved systems controls and /or security procedures developed by information systems/data processing, while $71.7 \%$ of them approved systems controls and /or security procedures developed by information systems/data processing. Fourty one Per cent of the 
respondents agreed that the information systems/data processing staff developed a prototype of the new system for me, while about $60 \%$ of them did not agree that the information systems/data processing staff developed a prototype of the new system for them. Only $27.6 \%$ of the respondents agreed that the information systems/data processing staff presented a detailed walk-through of the system procedures and processes for them, $72.4 \%$ of them did not agree that the information systems/data processing staff presented a detailed walk-through of the system procedures and processes for them.

Table 4: User Participation -Physical Design Phase

\begin{tabular}{|c|c|c|}
\hline Question & Yes & No \\
\hline $\begin{array}{l}\text { I had main responsibility for the development } \\
\text { project during physical design }\end{array}$ & $22(14.5 \%)$ & $130(85.5 \%)$ \\
\hline $\begin{array}{l}\text { Information systems/data processing staff drew up a } \\
\text { formalised agreement of the work to be done during } \\
\text { system physical design }\end{array}$ & $74(48.7 \%)$ & $74(48.7 \%)$ \\
\hline $\begin{array}{l}\text { I was able to make changes to the formlised } \\
\text { agreement of work to be done during system } \\
\text { physical design }\end{array}$ & $38(25 \%)$ & $114(75 \%)$ \\
\hline $\begin{array}{l}\text { The information systems/data processing staff kept } \\
\text { me informed concerning progress and/or problems } \\
\text { during system physical design }\end{array}$ & $73(48 \%)$ & $79(52 \%)$ \\
\hline I formally reviewed work done by information & & \\
\hline $\begin{array}{l}\text { system/data processing staff during system physical } \\
\text { design }\end{array}$ & $58(38.2 \%)$ & $94(61.8 \%)$ \\
\hline $\begin{array}{l}\text { I formally approved work done by information } \\
\text { system/data processing staff during system physical } \\
\text { design }\end{array}$ & $39) 25.7 \%)$ & $113(74.3 \%)$ \\
\hline $\begin{array}{l}\text { I signed off a formalised agreement of the work by } \\
\text { the information systems/data processing staff during } \\
\text { system physical design }\end{array}$ & $38(25 \%)$ & $114(75 \%)$ \\
\hline $\begin{array}{l}\text { For this system, I defined/helped define } \\
\text { input/output forms }\end{array}$ & $42(27.6 \%)$ & $110(72.4 \%)$ \\
\hline $\begin{array}{l}\text { For this system, I defined/helped define screen } \\
\text { layouts }\end{array}$ & $34(22.4 \%)$ & $118(77.6 \%)$ \\
\hline $\begin{array}{l}\text { For this system, I defined/helped define report } \\
\text { formats }\end{array}$ & $54(35.5 \%)$ & $98(64.5 \%)$ \\
\hline $\begin{array}{l}\text { I developed system controls and/or security } \\
\text { procedures for this system }\end{array}$ & $34(22.4 \%)$ & $118(77.6)$ \\
\hline $\begin{array}{l}\text { I evaluated systems controls and /or security } \\
\text { procedures developed by information systems/data } \\
\text { processing }\end{array}$ & $54(35.5 \%)$ & $98(64.5 \%)$ \\
\hline $\begin{array}{l}\text { I approved systems controls and /or security } \\
\text { procedures developed by information systems/data } \\
\text { processing }\end{array}$ & $39(25.7 \%)$ & $109(71.7 \%)$ \\
\hline $\begin{array}{l}\text { The information systems/data processing staff } \\
\text { developed a prototype of the new system for me }\end{array}$ & $62(40.8 \%)$ & $90(59.2 \%)$ \\
\hline $\begin{array}{l}\text { The information systems/data processing staff } \\
\text { presented a detailed walk-through of the system }\end{array}$ & $42(27.6 \%)$ & $110(72.4 \%)$ \\
\hline
\end{tabular}


procedures and processes for me

\subsubsection{User Participation - Implementation Phase}

Slightly more than a quarter of the respondents had a main responsibility for the development project during implementation, while $72.4 \%$ of them did not have a main responsibility for the development project during implementation. $61.2 \%$ agreed that the Information systems/data processing staff drew up a formalised agreement of the work to be done during system implementation, while $38.8 \%$ of them did not agree. Slightly over a quarter of the respondents were able to make changes to the formalised agreement of work to be done during system implementation, while $80.3 \%$ of them were not able to make changes to the formalised agreement of work to be done during system implementation. Close of $50 \%$ of the respondents agreed that the information systems/data processing staff kept them informed concerning progress and/or problems during implementation, while $51.3 \%$ of them did not agree that the information systems/data processing staff kept them informed concerning progress and/or problems during implementation. Also close to $50 \%$ of the respondents formally reviewed work done by information system/data processing staff during implementation, while 51.3 of them did not formally review the work done by information system/data processing staff during implementation.

About a third of the respondents formally approved work done by information system/data processing staff during implementation, while $69.7 \%$ of them did not formally approve work done by information system/data processing staff during implementation. Again about a third of the respondents signed off a formalized agreement of the work by the information systems/data processing staff during implementation while $64.5 \%$ of them did not sign off a formalized agreement of the work by the information systems/data processing staff during implementation. $36.2 \%$ of the respondents was involved in the development of test data specifications for this system, while $63.8 \%$ of them were not involved in the development of test data specifications for this system. $41.4 \%$ of the respondents reviewed the results of system tests done by the information systems/data processing staff, while $58.6 \%$ did not review the results of system tests done by the information systems/data processing staff. Slightly over a third of the respondents approved the results of system tests done by the information systems/data processing staff, while $63.8 \%$ of them did not approve the results of system tests done by the information systems/data processing staff. Sixty five per cent of the respondents agreed that the information systems/data processing staff held a 'special event' to introduce the system to them while $34.9 \%$ of them did not agree that the information systems/data processing staff held a 'special event' to introduce the system to them. More than a third of the respondents were trained in the use of the systems and were able to train other users on the use of the systems. Only $15.1 \%$ of the respondents designed the user-training program for this system, while $84.9 \%$ of them did not design the user-training program for this system, $20.4 \%$ of the respondents created the user procedures manual for this system, while $79.6 \%$ of them did not create the user procedures manual for this system. 


Question $\quad$ Yes No

I had main responsibility for the development project during implementation

$42(27.6 \%) \quad 110(72.4 \%)$

Information systems/data processing staff drew up a formalised agreement of the work to be done during system implementation

$93(61.2 \%) \quad 59(38.8 \%)$

I was able to make changes to the formalised agreement of work to be done during system implementation

$30(19.7 \%) \quad 122(80.3 \%)$

The information systems/data processing staff kept me informed concerning progress and/or problems during implementation

I formally reviewed work done by information system/data processing staff during implementation

$74(48.7 \%) \quad 78(51.3 \%)$

I formally approved work done by information system/data processing staff during implementation

$46(30.3 \%) \quad 106(69.7 \%)$

I signed off a formalized agreement of the work by the information systems/data processing staff during implementation

$46(30.3 \%) \quad 98(64.5 \%)$

I developed test data specifications for this system

$55(36.2 \%) \quad 97(63.8 \%)$

I reviewed the results of system tests done by the information systems/data processing staff

$63(41.4 \%) \quad 89(58.6 \%)$

I approved the results of system tests done by the information systems/data processing staff

$55(36.2 \%) \quad 97(63.8 \%)$ 
The information systems/data processing staff held a 'special event' to introduce the system to me

$99(65.1 \%) \quad 53(34.9 \%)$

I was trained in the use of this system

I designed the user training program for this system

I trained other users to use this system

$106(69.7 \%) \quad 46(30.3 \%)$

I created the user procedures manual for this system

$31(20.4 \%) \quad 121(79.6 \%)$

\subsection{User Involvement and Satisfaction Measurement}

This was measured by running ordinal regression model. The dependent variable was the transformed 7-point Likert scale response from user involvement and satisfaction measurement while the independent variables were all the user participation during the design and development phase and user participation in the implementation phase. The null hypothesis was that the user participation in both the design, development and implementation phases of health information systems does not influence the user involvement and satisfaction levels. The model fitting information results shows that there is a significant improvement in fit of the final model over the null model $[\chi 2(30)=280.571, p<.001]$. Further showing that the model fits the data very well.

Table 6 : Model Fitting Information

\begin{tabular}{llllll}
\hline Model & -2 & Log & Chi-Square & df & Sig. \\
& Likelihood & & & \\
\hline Intercept Only & 673.146 & & & & .000 \\
Final & 392.575 & & 280.571 & 30 & Sig. \\
Model & -2 & Log & Chi-Square & df & \\
\hline
\end{tabular}

\subsubsection{Parameter Estimates Testing}

Ordinal regression was run with the user involvement and satisfaction measure as the dependent 
variable and the user participation during the design and development of the health information systems as the independent variables. In interpreting the parameter estimates, the following independent variables had positive estimates. These include the following questions; Information systems/data processing staff drew up a formalised agreement of the work to be done during system physical design $($ Coeff $=74.799)$,

The information systems/data processing staff kept me informed concerning progress and/or problems during system physical design (Coeff=86.022), I formally reviewed work done by information system/data processing staff during system physical design (Coeff=124.956), For this system, I defined/helped define input/output forms (Coeff=398.075), I evaluated systems controls and /or security procedures developed by information systems/data processing (Coeff=193.119), I approved systems controls and /or security procedures developed by information systems/data processing $($ Coeff $=107.314)$, The information systems/data processing staff presented a detailed walk-through of the system procedures and processes for me (Coeff=18.917), I had main responsibility for the development project during implementation (195.711), The information systems/data processing staff kept me informed concerning progress and/or problems during implementation (Coeff=89.399), I formally approved work done by information system/data processing staff during implementation (Coeff=45.217), I approved the results of system tests done by the information systems/data processing staff, and I trained other users to use this system $($ Coeff $=62.535)$, I designed the user training program for this system (Coeff=161.238), and I trained other users to use this system $($ Coeff $=76.597)$.

This indicates that for every one unit increase in independent variable there is a predicted increase (of a certain amount) in the log odds falling at a higher level of the dependent variable. Generally showing that as scores increase on the independent variables, there is an increase probability falling at a higher level on the dependent variable. The following variable questions had negative estimates; I had main responsibility for the development project during physical design (Coeff=-10.072), I was able to make changes to the formlised agreement of work to be done during system physical design (Coeff=-143.392), I formally approved work done by information system/data processing staff during system physical design (Coeff=-135.923), I signed off a formalised agreement of the work by the information systems/data processing staff during system physical design (Coeff=-101.647), For this system, I defined/helped define screen layouts (Coeff=-105.379), For this system, I defined/helped define report formats(Coeff=-97.335), I developed system controls and/or security procedures for this system(Coeff=-247.148), The information systems/data processing staff developed a prototype of the new system for me $(\operatorname{Coeff}=-10.710)$, Information systems/data processing staff drew up a formalised agreement of the work to be done during system implementation (Coeff=-88.224), I was able to make changes to the formalised agreement of work to be done during system implementation (Coeff=-85.384), I formally reviewed work done by information system/data processing staff during implementation(Coeff=-7.716), I signed off a formalized agreement of the work by the information systems/data processing staff during implementation (Coeff=-96.873), I developed test data specifications for this system (Coeff=-232.323), I reviewed the results of system tests done by the information systems/data processing staff (Coeff $=-4.759)$, The information systems/data processing staff held a 'special event' to introduce the system to me(Coeff=-8.239), and I was trained in the use of this system(Coeff=-75.959).

This indicates that for every one unit increase on an independent variable there is a predicted decrease (of a certain amount) in te log odds of falling at a higher level of the dependent variable. In general, as the scores increase on the independent variables, there is a decreased probability of falling at a higher level on the dependent variable. 


\subsubsection{Test of Parallel Lines}

The null hypothesis states that the location parameters (slope coefficients) are the same across response categories. The results of the test of Parallel lines (ie assumption of proportional odds) indicate non-significant 0.976 , showing the assumption is satisfied. This means that all the independent variables are associated with the dependent variable.

Table 7: Test of Parallel Lines

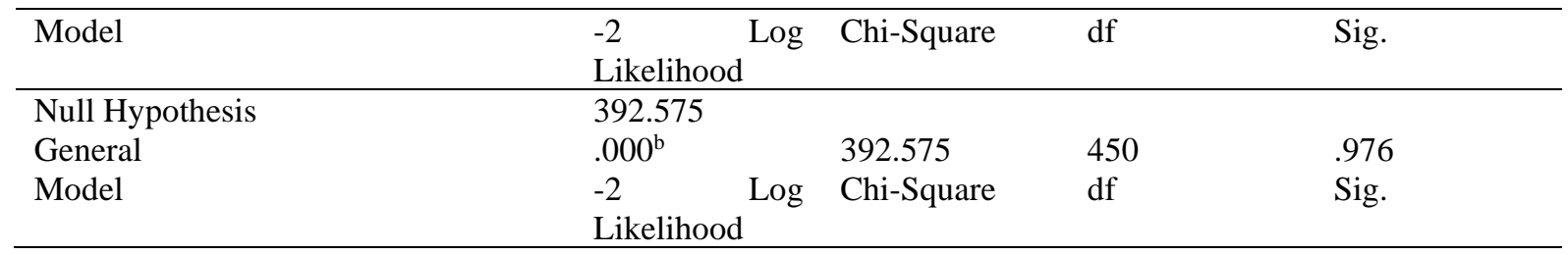

\section{DISCUSSIONS AND CONCLUSIONS}

\subsection{User involvement and satisfaction levels in health information systems during the design and development phase}

User involvement is widely accepted principle in the design development of usable systems. Many people think that design phase is only for technical skills of developer as opposed to end users (Sun, 2013). User can help developers build documents files as reference for the new systems, also make a balance between the technical aspect and the simplification aspects as well. Currently user requirements may keep changing thus resulting to the new developed systems drop behind the requirements (Sun, 2013). Developers must keep in close contact with the users and get the latest requirements from them so that they can amend their design reasonably to align to the requirements.

According to Damodaran (1996) a number of studies have demonstrated that effective user involvement in systems design yields the following benefits to the user and also to the organization at large i) User involvement leads to improvement of the quality of the system due to more accurate user requirements provided to the team, ii) user involvement help eliminate some very costly systems features that the user might not want or might not use or will not use at all, iii) user involvement raises the acceptance and satisfaction levels of the system, iv) Leads to greater understanding of the systems by the user resulting in more effective use and v) user involvement leads to increased participation in decision making within the organization. Better effort at the early stages of the design process as this leads to much less effort later on and a good system at the end (Kujala, 2003)

During the design and development of health information systems there is a general understanding that users need to be fully involved in all stages of processes. This in return build their confidence, participation and satisfaction level of the health information systems being developed. The study measured using questions whether users were involved and their satisfaction levels in the developed health information systems during the design and development stages, both at the physical design and implementation stages.

\subsection{User Participation during the physical design stage}

Firstly, more respondents did not have main responsibilities during the physical design of the health information systems. Develop. This demonstrates that the developers did not particularly assign users key responsibilities during the physical design stage. Secondly, the study revealed that equal number of 
participants agreed and disagreed that the Information systems/data processing staff drew up a formalised agreement of the work to be done during system physical design, illustrating un-clear position to the extent of developers' engagement with the users. Similarly very few respondents were able to make changes to the formlised agreement of work to be done during system physical design, this implies that HIS developers do not allow users any chances to make any changes to the physical design of the systems. Thus, the systems are designed without users view incorporated.

Fourthly, the study revealed that information systems/data processing staff only kept less than half of respondents informed concerning progress and/or problems during system physical design to some extent close to half of the time. This is very critical in terms progress of physical design processes. Very few respondents were formally engaged in reviewing the work done by information system/data processing staff during system physical design, again this puts the entire system product in jeopardy, as the users input is not included. During reviewing the work, the development team give the users an opportunity to raise any questions and concerns and expectation of the systems. Generally, this is very health for the development teams as their mindset differs greatly with that of the users and they would benefits from the users' reviews since they are actual and final users of the system. Again, the study find out that few respondents formally approved the work done by information system/data processing staff during system physical design; this implies that the information system/data processing staff did not seek approval from the users to proceed the physical design of the system. This deprives the information system/data processing staff opportunity to get critical input from the users.

From the sampled respondents few of them signed off a formalised agreement of the work by the information systems/data processing staff during system physical design, this implies that they were not fully involvement in the design work thus not able to approve and sign off. This make the information systems/data processing staff loss the benefits of the user involvement to the system design process. In terms of ability to help in defining output forms, screen layouts, report formats, development of systems controls and security procedures for the health information systems, less respondents were involved and able to perform these processes. Users are core to the input of the outputs and format of both the system input forms and the outputs forms since they are the final consumers. The study revealed that fewer respondents evaluated systems controls and /or security procedures developed by information systems/data processing contrary to the requirement and guidelines, only about $26 \%$ of the respondents approved systems controls and /or security procedures developed by information systems/data processing, this implies the insufficient user involvement of the current health information system design and development processes.

Depending on the systems development model prototype is essential as it enable to the users to evaluate the progress of the development process. This findings of this study established that less than half of the respondents had the opportunity to evaluate the prototypes of the systems. This eventually leads to system products with errors that could have been identified during development using prototypes. Thus, increases the costs of providing usable systems as the information systems/data processing will need to go back and forth to ensure concurrence to the user requirements. Similarly less than a third of the respondents agreed that the information systems/data processing staff presented a detailed walk-through of the system procedures and processes for them, impounding the lack of walkthrough in terms of soliciting for user input early in the physical design stage. 


\subsection{User Participation during the Implementation stage}

Even through developers always test the system any times, user have the final right to evaluate whether the new system is satisfactory (Sun, 2013). Developer has to continually communicate with the user to get to know what they think about the system. They also need to provide education and training for users; through these, they get good communication opportunity for feedback from the users. At the end of implementation phase acceptance testing, this is when users feel assured that the new system is developed according to their expectations and fully meet their requirements.

The study established that slightly more than a quarter of the respondents had a main responsibility for the development project during implementation, this imply that the development team do not fully assign responsibility to the users of the systems during the implementation stage. System developer are required to collectively with the users draw up formalised agreement of the work to be done during the systems implementation. The study revealed that more than half of the respondents had the opportunity to participate in the drawing up of the agreement. Slightly over a quarter of the respondents were able to make changes to the formalised agreement of work to be done during system implementation, this little comparative proportion suggest that the developer did not allow the respondents to make changes to the formalised agreement of work during the systems implementation stage. Since the users are very important in the implementation phase, an opportunity needs to be granted to them to discuss, suggest and make changes to the agreement of work to be done during system implementation. In terms of keeping the users informed concerning progress and/or problems during implementation, the developer performed averagely well at 50 per cent. This however need to be improved in future systems development. Users need to be a hundred percent informed concerning progress and/or problems during implementation.

More respondents did not formally review the work done by information system/data processing staff during implementation than those who had formally reviewed work done by information system/data processing staff during implementation. This too highlight a gap in terms to engage the users in reviewing the work done by the developer during the implementation phase. About three quarters of the respondents formally did not approved work done by information system/data processing staff during implementation. This shows that the developers were working on their own with little engagement with the users contrary to the requirements. Since users were not fully involvement on the work during the systems implementation phase, More users did not sign off a formalized agreement of the work by the information systems/data processing staff during implementation. Similarly, less users were involved in the development of test data specifications for the system and reviewed the results of system tests done by the information systems/data processing staff.

Since the respondents were not involvement in the test data, they did not approved the results of system tests done by the information systems/data processing staff. Sixty five per cent of the respondents agreed that the information systems/data processing staff held a 'special event' to introduce the system to them. This shows that apart from not involving the users in a number of processes the development team had the opportunity to organize a special even to introduce the system. Similarly less and less users were involved in the training of the other users of the systems, designed the user training programs and also were involved in the creation of the user procedures manual for the system.

\subsection{Users Involvement and Satisfaction Measurement}

Users are the first members of a team in an organized systems developed team. User may participate in 
data gathering, data flow diagrams development and reviews and use prototyping (Sun, 2013). User involvement can further results in to the following benefits.

- Through user involvement the systems developer is able to identify the current problems that might be neglected because of lack of the environment understanding (Sun, 2013). Since users are constantly interacting with the perceived environment where the new systems will be deployed, this gives them a very good opportunity to describe it better to the development team for incorporation into the system.

- Through user involvement conflicts between users and development team. When they are involved throughout the process the development team can communicate with tem at any time for meeting latest needs and improve the systems (Sun, 2013).

- According to Dodd and Carr, 1994 jointly involving the users and the development team helps to create an understanding of why trade-offs are made. If this is not done users may at the end decline to approve the product citing that the system is not aligned to their requirements. Immediate feedback is required from the users on real time during the development of the system. For instance if they find any mismatch between the design and the expected requirements thus making trade-off very reliable and reasonable (Sun, 2013).

- User involvements enable user to lean the systems better besides the development benefits. They gain an opportunity to lean and study the new system, because it is a part of its creation, thus contribute to further systems implementation phase (Sun, 2013). It improves their computer literacy levels as well.

- Through user involvement, the development get many insights into how individual work affects the organization department. Both of them become attuned to the systems perspectives of the whole organization, leading a very efficient integration within the organization and work become more efficient (Sun, 2013).

\subsubsection{Relationship Between User Involvement, Satisfaction Measurement and User Participation during the physical design and implementation phases of systems development.}

Through an ordinal regression model where the dependent variable ie user involvement and satisfaction measurement was the transformed 7-point Likert scale response and the independent variables ie user participation during the design and development phase and user participation in the implementation phase. With the null hypothesis was that the user participation in both the design, development and implementation phases of health information systems does not influence the user involvement and satisfaction levels. The model fits information showed the model fitted the data very well $\left[\chi^{2}(30)=280.571, p<.001\right]$. This demonstrate that the ordinal regression analysis was best choice of statistical systems to help answer the question. In general, user participation has position impact on the satisfaction level of users during the design and development of the system.

From the results a number of questions had positive coefficients indicating that for every one unit increase in independent variable there is a predicted increase (of a certain amount) in the log odds falling at a higher level of the dependent variable. Generally showing that as scores increase on the independent variables, there is an increase probability falling at a higher level on the dependent variable. For example as the scores of whether the development team drew up a formalised agreement of the work during the physical design increases, there an increased probability falling a higher level on the user satisfaction level $($ Coeff $=74.799)$. As a component of participation, drawing up the agreement of the work together positively contributes to the user satisfaction level during the development process and with the final product. As to whether the development team kept the user informed concerning the progress and problems during the physical design stage, this too has a positive parameter estimate (Coeff=86.022) implying a 
position relationship with user satisfaction levels. Formally reviewing work done by the development team during the physical design stage, helping define input/output forms, evaluating control and security procedures developed by the developed team.

Additionally results from the following questions yielded positive parameter estimates. Approving the systems control and/or security procedures developed by the development team, ability of the development team to present a detailed walk-through of the system procedures and processes, the user being informed concerning the progress and/or problems during implementation phase, approving the work done and results during the implementation stage, training of users and designing training programs, all these influence positively the user satisfaction levels. These demonstrate the important aspects of engaging the users in all processes of the development of an information system.

A number of questions also yielded negative parameter estimates. These largely relate to aspects of implementation. These imply that the aspects are not necessarily critical at implementation stage and underscores the need to have some of these practiced during the physical design stages. The results from the regression analysis model established that for every one-unit increase on these independent variables listed below, there is a predicted decrease (of a certain amount) in the log odds of falling at a higher level of the dependent variable. In general, as the scores increase on the independent variables, there is a decreased probability of falling at a higher level on the dependent variable. The results of the test of Parallel lines (ie assumption of proportional odds) indicate non-significant 0.976, showing the assumption is satisfied. This means that all the independent variables are associated with the dependent variable. Thus, the researcher rejected the null hypothesis that stated that there is no relationship between user participation during the physical design and implementation and the user involvement and satisfaction.

\section{References}

Ada, S., Sharman, R., \& Gupta, M. (2009). Theories Used in Information Security Research: Survey and Agenda. Information Science Conference(an imprint of IGI Global).

Almunawar, M. N., \& Anshari, M. (2012). Health Information Systems (HIS): Concept and Technology . ResearchGate.

Anderson. (1973). THEORIES OF CUSTOMER SATISFACTION.

Andreas M. Kaplan, \& Haenlein, M. (2010). Users of the world, unite! The challenges and opportunities of Social Media . 1-2.

Anthony J. Onwuegbuzie, \& Johnson, R. B. (2006). The Validity Issue in Mixed Research . Research in the School, Vol 13, No. 1, 48-63.

Banks, V. A. (2018). Development of a Usability Evaluation Framework for the flight deck.

Barki, H., \& Hartwick, J. (1994). Measuring user participation, user involvment and user attitude. MIS Quarterly;

Bernérus, A. (2010). A Peek at the Position of Pedagogical Aspects in Usability Evaluation of Elearning System .

Bevan, N. (2009). International Standards for Usability Should Be More Widely Used. Journal of Usability Studies.

Blecken, A. (2010). Usability Evaluation of a Learning Management System.

Brien, H. L., \& Toms, E. G. (2008). What is User Engagement? A Conceptual Framework forDefining User Engagement with Technology. 
Brook, C. (2020, March). Retrieved from https://digitalguardian.com/author/chris-brook: https://digitalguardian.com/author/chris-brook

Browne, E. (2015). Social media and governance. Helpdesk Research Report, 1-2.

Buntin, M. B. (2011). The Benefits Of HealthInformation Technology: A ReviewOf The Recent Literature ShowsPredominantly Positive Results.

Butt, S. M., \& Ahmad, W. F. (2012). An Overview of Software Models with Regard to the Users Involvement.

Chen, S. (2011). INFORMATION SYSTEMS EVALUATION METHODOLOGIES. White Rose Research Online.

Constantine, L. (2002). Usage-centered engineering for Web applications. IEEE Software .

Cooper, A. (2003). The Essentials of Interaction Design.

Davis, F. D. (1985). A Technology Acceptance Model for Empirically Testing New End-User Information Systems. ResearchGate.

Duin, D. H. (2014). Usability Themes in Open Source Software.

E. Borycki, A. K. (2013). Usability Methods for Ensuring Health Information Technology Safety: EvidenceBased Approaches.

Earthy, J. (2009). ISO standards for user centered design and the specification.

Farbey, B., \& Land, F. (1992). Evaluating investments in IT. Journal of Information Technology , 109-122.

Feng-HanLin. (2017). EmpiricalresearchonKano'smodelandcustomersatisfaction. YongDeng,SouthwestUniversity,CHINA.

Florence Femi Odekunle, R. O. (2017). Why sub-Saharan Africa lags in electronic health record adoption and possible strategies to increase its adoption in this region. Qassim University.

Francis Lau, C. K. (2016). Handbook of eHealthEvaluation. Canada: Published by University of Victoria.

Fulop, S. A., \& Chater, N. (2013). Learnability theory . Wiley Interdiscip Rev Cogn Sci. 2013 May;4(3):299306.

Golafshani, N. (2003). Understanding Reliability and Validity in Qualitative Research. Creative Commons Attribution-Noncommercial.

Guido G., \& R., I. (2011). A Modelling and Reasoning Framework for Social Networks Policies.

Halawi, L., \& McCarthy, R. (2006). Which Theory Applies: An Analysis of Information Systems Research. ssues in Information Systems, 7(2).

Hallikainen, P., \& Chen, L. (2006). A Holistic Framework on Information Systems Evaluation with a Case Analysis. Electronic Journal of Information Systems Evaluation Volume 9 Issue 22006 (57 - 64), 57 64.

Hartoyo, \& Simanjuntak. (2017). The Impact of Product Quality, Service Quality, and Customer Loyalty Program perception on Retail Customer Attitude. Independent Journal of Management \& Production - September 2017.

HEALTHCARE SYSTEMS: SUPPORTING AND ADVANCING CHILD HEALTH. (2010). Journal of Hospital Medicine.

Hevner. (2004). DESIGN SCIENCE IN INFORMATIONSYSTEMS RESEARCH.

Hovland, C. I., Harvey, O. J., \& Sherif, M. (1957). Assimilation and contrast effects in reactions to communication and attitude change. The Journal of Abnormal and Social Psychology, 55(2), 244252.

https://www.usabilitybok.org. (2020, 08 03). Usability Body of Knowledge. Retrieved from User Experience Professionals' Association: https://www.usabilitybok.org/

James R. L., \& M., T. H. (2001). Handling of Non-Reponse in Social Science Research. Journal of Agricultural Education Vol 42 No. 4, 43-53.

Jeff Rubin, D. C. (2008). Handbook ofUsability Testing. Boulevard: Wiley Publishing, Inc.

Jensen, W. \&. (2016). User-centred Design and Evaluation of Health Information Technology. 
Johnson, C. M. (2005). A user-centered framework for redesigning health care interfaces.

Johnson, R. B. (2007). Toward a Definition of Mixed Methods Research. . Journal of Mixed Methods Research 1, 112-133. April 2007.

Kaplan, A. M., \& Haenlein, M. (2012). Social media: back to the roots and back to the future. Journal of Systems and Information Technology, Vol. 14 Issue: 2, 101-104.

Kearsley, G., \& Shneiderman, B. (1998). Engagement Theory: A Framework for Technology-Based Teaching and Learning. Educational Technology Publications, Inc.

Kin-Nam L., Kam-Hon L., \& H., Y. (2005). Text Mining for the hotel industry.

Kujala, S. (2003). User involvement: A review of the benefits and challenges. behavior and Information Technology, 2003, Vol 22.

Kuper, A. (2008). Critically Appraising Qualitative Research. BMJ (online) · February 2008.

L Safko, \& Brake, D. (2009). The social media bible.

Leora H. L., Barbara W. F., \& L., R. (2010). How Are Hotels Embracing Social . HVS Sales and Marketing Services.

Lestari, V. A. (2017). Development Framework for the Evaluation of Usability in E-Government: A Case Study of E-Finance Government of Malang.

Lipika D., Mirajul H., \& S., A. K. (2011). Acquiring Competitive Intelligence from Social Media.

Maarit Mäkinen, \& Kuira, M. W. (2008). Social media and Postelection in Kenya. The International Journal of Press/Politics.

Manuel, J., Pastor, J., \& Casanovas, J. (2003). A GOAL/QUESTION/METRIC RESEARCH PROPOSAL TO MONITOR USER INVOLVEMENT AND PARTICIPATION IN ERP IMPLEMENTATION PROJECTS . Information Resources Management Association Conference (IRMA), Philadelphia (USA), May 2003, pp. 325-327.

Marcial, L. (2014). Usability in Healthcare: A 'Wicked' Problem'.

Mary J. C., Patrick J. M., \& Z., J. I. (2010). How Large U.S. Companies Can Use Twitter and Other Social Media to Gain Business Value. MIS Quarterly Executive.

Maryati, M. (2008). Investigating evaluation frameworks for health information systems.

Mkpojiogu, \& Hashim. (2016). Understanding the relationship between Kano model's customer satisfaction scores and self-stated requirements importance. SpringerPlus (2016) 5:197.

Mohd, \& Maryati. (2006). Towards a Framework for Health Information Systems Evaluation. Proceedings of the 39th Hawaii International Conference on System Sciences. Middlesex, UB8 3PH, UK.

Mohd, M. (2008). Investigating evaluation frameworks for health information systems.

Morville, P. (2004). User Experience Design.

Muinga, N. (2020). Digital health Systems in Kenyan PublicHospitals: a mixed-methods survey.

Mutula. (2012). E-government: challenges and opportunities in Botswana. International journal of humanities and social sciences.

Nandikove, P. N. (2018). Technical Factors Affecting Electronic Medical Record System . ResearchGate.

Nielsen, J. (1993). Usability Engineering. California: Morgan Kaufmann.

Novalija I., Miha P., \& M., D. (2014). TOWARDS SOCIAL MEDIA MINING. Twitterobservator.

OM Mugenda, \& Mugenda, G. (2003). Research methods Quantitative and Qualitative .

Palm, J.-M. (2006). Determinants of User Satisfaction with a Clinical Information System., (p. AMIA 2006 Symposium Proceeding).

Palm, J.-M., Colombe, I., Sicotte, C., \& Degoulet, P. (n.d.). Determinants of User Satisfaction with a Clinical Information System . AMIA 2006 Symposium Proceedings.

Paul M. Di G., Molly M. W., \& H., R. E. (2010). Getting Customers' Ideas to Work for You: Learning from Dell, How to succeed with online user innovation community. MIS Qaurterly Executive.

PH Keckley, \& Hoffman, M. (2010). Social networks in health care: Communication, collaboration and insights. Deloitte Centre for Health Solutions. 
Preece, J. (2002). Interaction Design: Beyond Human Computer Interaction.

Qualman, E. (2009). How social media transforms the way we live and do business.

Raj M Ratwani. (2016). A framework for evaluating electronic health record vendor user centered design and usability testing processes.

Rajanen, D. (2014). Usability Evaluation of Information Systems: A Review of Five International Standards. Research Gate.

Reza Zafarani, Mohammad Ali Abbasi, \& Liu, H. (2014). Social Media Mining: An Introduction. In Reza Zafarani, Mohammad Ali Abbasi, \& H. Liu, Social Media Mining: An Introduction (pp. 28-35). London: Camdrige University Press.

Robert F., Stephanie W., \& P., J. (2009). Censorship 2.0.

Roberts, M. (2018). Successful Public Health Information System Database Integration Projects: A Qualitative Study.

Rodrigues, A. J. (2004). HEALTH INFORMATICS: IMPLICATIONS OF EVALUATION MODELS FOR DEVELOPING COUNTRIES. African Society for Biomathematics series, 5-8.

Saarinen, T., \& Vepsäläinen, A. (1993). Managing the risks of information systems implementation. European Journal of Information Systems volume 2, 283-295.

Sebastian V., Namsu P., \& F.K, K. (2009). Is There Social Capital in a Social Network Site?: Facebook Use and College Students' Life Satisfaction, Trust, and Participation. Computer- Mediated Communication.

Sebetci, Ö. (2018). Enhancing end-user satisfaction through technology compatibility: An Assessment on Health Information. Health Policy and Technology.

Shirer, M. (2020, February). https://www.idc.com. Retrieved from https://www.idc.com: https://www.idc.com/getdoc.jsp?containerId=prUS46047320

Sood, S. (2008). Electronic Medical Records: A Review Comparing the Challenges in Developed. Research Gate.

Suh, A., \& Cheung, C. M. (2019). Revisiting User Engagement: Concepts, Themes, and Opportunities. Twenty-Third Pacific Asia Conference on Information Systems, China 2019.

Sun, Z. (2013). User Involvement in System Development Process. Published by Atlantis Press, Paris, France.

Sylla, C., \& Wen, H. J. (2002). A conceptual framework for evaluation of information technology investments . International Journal of Technology Management Volume 24, Issue 2-3.

Tahir, R. (2014). Framework for Evaluating the Usability of Mobile Educational Applications for Children.

Tanga, T., Limc, M. E., Mansfieldc, E., McLachlanf, A., \& Quanc, S. D. (2018). Clinician user involvement in the real world: Designing an electronic tool to improve interprofessional communication in a hospital setting. International Journal of Medical Informatics.

Tierneya, W. M. (2010). Experience Implementing Electronic Health Records. MEDINFO.

Tofan, D. C. (2011). Information Security Standards. Journal of Mobile, Embedded and Distributed Systems, vol. III, no. 3, 2011.

TYLLINEN, M. (2018). A Framework for Usability Evaluation in EHR Procurement.

Vanderdonckt, J. (1999). Development milestones towards a toolfor working with guidelines.

Vanderdonckt, J. (2013). State of the Art of Web Usability Guidelines.

Velde, R. V. (2010). Clinical Information Systems: A component Based Approach. In Health Informatics.

Weiguo Fan, \& Gordon, M. D. (2014). The Power of Social Media Analytics. Communications of the ACM, Vol. 57 No. 6, 74-81.

William Lidwell, K. -H. (2003). Universal Principles of Design. Rockport Publishers, Inc.

William, B. (2013). Assessment of the Health IT Usability Evaluation Model (Health-ITUEM)for evaluating mobile health (mHealth) technology. 
Wu He, Shenghua Zha, \& L., L. (2011). Social Media compeitive analysis and Text mining: A case study of Pizza industry. International.

Xavier, F. (2014). Integration of Usability Techniques into the Software Development Process. ResearchGate. Yampolskiy, R. (2011). Efficiency Theory: a Unifying Theory for Information, Computation and Intelligence. Journal of Discrete Mathematical Sciences and Cryptography.

Yen, P.-Y. (2010). Health Information Technology Usability Evaluation: Methods, Models, and Measures.

Yüksel, A., \& Yüksel, F. (2008). Consumer Satisfaction Theories: A Critical Review. Nova Science Publishers, New York, 2008.

Zhang, J. (2011). TURF: Toward a unified framework of EHR usability. Journal of Biomedical Informatics. 